\title{
Attesting the efficiency of monitored natural attenuation in the detoxification of sewage sludge by means of genotoxic and mutagenic bioassays
}

\author{
Dânia Elisa Christofoletti Mazzeo, Thaís Cristina Casimiro Fernandes, \\ Maria Aparecida Marin-Morales* \\ Department of Biology, Institute of Biosciences, UNESP - Univ Estadual Paulista, Av. 24-A, 1515, 13506-900, Rio Claro, SP, Brazil
}

\section{H I G H L I G H T S}

- Genotoxicity/Mutagenicity of urban sewage sludge in HepG2 cells and Salmonella tests.

- Mutagenic effect of the studied sewage sludge observed in Salmonella strain TA 100/S9.

- Sludge/soil associations induced micronuclei in human hepatoma cell line.

- Natural attenuation detoxifies sludge and decreases potential risks to human health.

\section{A R T I C L E I N F O}

\section{Article history:}

Received 12 October 2015

Received in revised form

30 June 2016

Accepted 13 August 2016

Available online 25 August 2016

Handling Editor: Frederic Leusch

\section{Keywords:}

Solid waste

In vitro test

HepG2 cells

Salmonella assay

Micronucleus
G R A P H I C A L A B S T R A C T

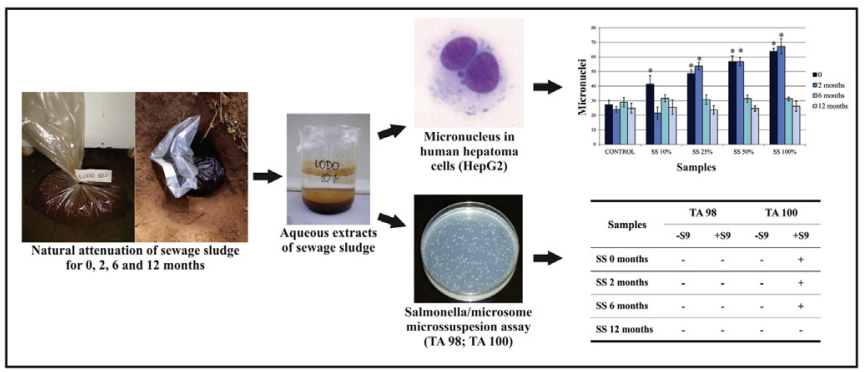

\begin{abstract}
A B S T R A C T
A viable alternative to the use of sewage sludge (SS) would be using it as a reconditioner of agricultural soils, due to its high content of organic matter and nutrients. However, this solution may contaminate the soil, since SS may contain toxic substances. Monitored natural attenuation is a process that can be used in the decontamination of SS before its disposal into the environment. The effectiveness of the natural attenuation of a domestic SS was evaluated over 12 months by assays of Salmonella/microsome and micronucleus (MN) in human hepatoma cells (HepG2). Mutagenic activity was observed for the Salmonella strain TA 100, with S9, for the extracts from periods 0-6 months of natural attenuation. Genotoxic effects were observed in HepG2 cells, for 0 and 2 months, in almost all tested concentrations. Comparing obtained data by MN test to chemical analyses, it is possible to observe a coincidence between the induction of MN and the quantity of the $\mathrm{m}$ - and p-cresol, since these compounds were present in the initial SS and after 2 months of natural attenuation, decreasing their concentrations in samples from 6 to 12 months. The positive results obtained with Salmonella/microsome (from 6 months) suggest a combined action of other substances in SS. These results indicated that this SS, in the earlier periods tested, is potentially genotoxic and mutagenic and that its disposal can lead to severe environmental problems. Thus, the use of the studied SS as reconditioner requires pre-processing for over than 6 months of natural attenuation.
\end{abstract}

() 2016 Elsevier Ltd. All rights reserved.

\footnotetext{
* Corresponding author. Departamento de Biologia, Instituto de Biociências, Universidade Estadual Paulista (UNESP), Av. 24-A, 1515, CP 199, 13506-900, Rio Claro, SP, Brazil.

E-mail addresses: daniamazzeo@gmail.com (D.E.C. Mazzeo), tccfbio@rc.unesp.br (T.C.C. Fernandes), mamm@rc.unesp.br (M.A. Marin-Morales).
}

\section{Introduction}

With increasing urban development and the increase in the 
number of inhabitants, the world population is facing a serious environmental problem regarding the fate of solid waste generated by wastewater treatment plants (Pathak et al., 2009). Each year, worldwide, millions of tons of sewage sludge (SS) are produced (Aparicio et al., 2009) with the prospect of increased production.

Since SS contains high concentrations of organic matter, micronutrients and macronutrients, such as nitrogen and phosphorus, it has been considered as an excellent material for the reconditioning of agricultural soils (Çifci et al., 2013). However, SS may present a high variability of persistent and bioaccumulative toxic compounds, which, when deposited in the environment, may compromise the quality of soils and associated environment, such as atmosphere, subterraneous and superficial waters (Cincinelli et al., 2012). The exposure of plants and animals to these pollutants may compromise the trophic chain (Roig et al., 2012), as well as represent risks to the human health.

In an attempt to ensure the chemical and biological stability of SS and avoid harmful environmental consequences generated by its application on soil, several methods have been presented to decontaminate SS (Rathod et al., 2009). Among these methods, natural attenuation may decrease the concentration of some pollutants in the environment by means of natural processes, such as volatilization, transformation, dilution, dispersion (Megharaj et al., 2011), and mainly by biodegradation by the microorganisms present in the contaminated site. Thus, this process has been considered an advantageous method with low-cost implantation (Mills et al., 2003).

To better characterize the toxic substances present in SS, the association between chemical analysis and bioassays are strongly recommended (Farré and Barceló, 2003). Among the several bioassays available, the Salmonella/microsomal test has been widely used for the detection of the mutagenic potential of a large variety of chemicals, including complex environmental samples, due to its simplicity, fastness, efficiency and high reproducibility (Claxton et al., 2010).

The micronucleus test (MN test) has been extensively used to evaluate the genotoxic effects induced by SS (Tewari et al., 2005; Solano et al., 2009; Gajski et al., 2011) because it is a high sensitive and efficiency in the detection of biological effects of environmental pollutants. Moreover, the induction of MN is considered an indicative of cancer risk in humans (Bonassi et al., 2007).

Since the liver plays the main role in the detoxification of xenobiotics, human liver cells (HepG2) have been commonly used in environmental genotoxicity studies (Baderna et al., 2013), especially by closely resembling the characteristics of in vivo human cells (Van Der Water et al., 2011).

This study investigated the genotoxic effect of an urban SS, by means of the MN test, performed with human liver culture cells (HepG2), as well as its mutagenic potential by Salmonella/microsomal assay, after several periods of monitored natural attenuation. The effectiveness of this process was evaluated through the decreasing of the SS toxic activity over the periods of natural attenuation on the studied test-systems.

\section{Materials and methods}

\subsection{Obtaining the samples}

The studied SS was collected at a domestic sewage treatment plant, located at the municipality of Rio Claro (in the state of São Paulo, Brazil). After sampling, part of this SS was mixed with a clay soil control $(146.7 \mu \mathrm{S} / \mathrm{cm})$, in proportions of $10 \%, 25 \%$ and $50 \%(\mathrm{v} / \mathrm{v})$. The soil was collected in the Experimental Garden of the University of São Paulo State-UNESP (Rio Claro, São Paulo State, Brazil), being considered as a reference soil (environmental control) due to its absence of toxicity and so, suitable to be used in this experiment.

All samples (10\%, 25\%, 50\% and 100\% SS) were then disposed, in duplicate, in plastic bags that were micro-perforated with $0.5 \mathrm{~mm}$ diameter holes $1 \mathrm{~cm}$ apart from each other, and buried in an uncontaminated site for periods of $0,2,6$ and 12 months, in order to promote a natural attenuation of the samples, as described by Mazzeo et al. (2015).

The chemical characterization of the $100 \%$ SS, regarding the presence of chlorinated benzenes, phthalates, chlorinated and nonchlorinated phenols, polycyclic aromatic hydrocarbons, chlorinated dioxins and pesticides, after each period of natural attenuation, indicated that the studied samples contained the organic compounds shown in Table 1. A complete chemical characterization of the samples can be seen in Supplementary data.

\subsection{Preparation of aqueous extract of SS (solubilized)}

To obtain an aqueous extract of SS, $125 \mathrm{~g}$ of each sample (10\%, $25 \%$ and $50 \%$ SS), regarding to their dry weight, were mixed in $500 \mathrm{~mL}$ of ultra pure water, which was followed by low-speed constant stirring for $5 \mathrm{~min}$, according to ABNT NBR 10.006 (2004). Due to the high hygroscopic potential of the $100 \%$ SS, twice the volume of water $(1000 \mathrm{~mL})$ used for other samples $(10 \%, 25 \%$ and $50 \% \mathrm{SS}$ ) was added to the same mass (125 g) of $100 \% \mathrm{SS}$, in order to obtain a similar supernatant liquid phase.

After 7 days of decantation, the supernatant was collected and filtered through a membrane of $0.45 \mu \mathrm{m}$ porosity. With this procedure, aqueous extracts of each studied samples containing soluble substances, potentially bioavailable, were obtained. The presence of hydrophilic compounds with biological activity in these extracts was tested by bioassays of genotoxicity and mutagenicity.

Previous analyses using high performance liquid chromatography with diode array detection (HPLC-DAD) showed that the aqueous extracts related to the $100 \%$ SS samples presented a mixture of $m$ - and $p$-cresol in concentrations of $3.70 \mathrm{mg} / \mathrm{L}, 4.21 \mathrm{mg} /$ $\mathrm{L}, 0.78 \mathrm{mg} / \mathrm{L}$ and $0.06 \mathrm{mg} / \mathrm{L}$ for the periods of $0,2,6$ and 12 months of natural attenuation, respectively (Mazzeo et al., 2015).

\subsection{Salmonella/microsome microsuspension assay - Kado test}

S. typhimurium strains TA98 and T100 were used in this study, with and without the metabolizing fraction, to detect frameshift mutations and substitution mutations at base pairs, respectively.

This test was based on the protocol described by Kado et al. (1983). The strains TA98 and TA100 were cultivated overnight in nutrient broth, in a shaker incubator, at $37^{\circ} \mathrm{C}$. Following this procedure, $100 \mu \mathrm{L}$ of each strain ( $10^{10}$ cells $/ \mathrm{mL}$ ) were added to culture tubes containing $100 \mu \mathrm{L}$ of phosphate buffer $0.1 \mathrm{M}$ and the volume of the sample, corresponding to concentrations of $6.25,12.5,18.75$, $25.00,37.50$ and $50.00 \mathrm{mg}$ dry SS equivalent. These concentrations were obtained by diluting the $100 \%$ SS aqueous extract.

For the assays with S9 metabolic activation, the phosphate buffer was replaced by $100 \mathrm{~mL}$ of S9 mix [sterilized distilled water, phosphate buffer $0.2 \mathrm{M}$, NADP $0.1 \mathrm{M}$, glucose-6-phosphate $1.0 \mathrm{M}$, solutions of salts ( $\mathrm{KCl} 1.65 \mathrm{M}$ and $\left.\mathrm{MgCl}_{2} 0.4 \mathrm{M}\right)$ and S9 fraction]. The tubes containing the mixture were pre-incubated at $37{ }^{\circ} \mathrm{C}$ for $90 \mathrm{~min}$. Thus, their contents, already with the addition of $2 \mathrm{~mL}$ of surface agar, were poured in sterilized Petri dishes containing minimum solidified agar. The Petri dishes were incubated at $37{ }^{\circ} \mathrm{C}$ for $72 \mathrm{~h}$. Each test was run in triplicate.

To perform the assay with metabolic activation, an exogenous metabolic activation system was used (S9 microsomal system, Moltox), composed of a homogenate of Sprague-Dawley rat liver cells, pretreated with polychlorinated biphenyl mixture (Araclor 1254). 
Table 1

Chemical characterization of the reference soil and the SS $100 \%$ after different periods of monitored natural attenuation.

\begin{tabular}{|c|c|c|c|c|c|c|c|}
\hline Parameter & Unit & Reference soil & Initial sample & 2 months sample & 6 months sample & 12 months sample & $\begin{array}{l}\text { Maximum value allowed by } \\
\text { legislation (CONAMA 375) }\end{array}$ \\
\hline \multicolumn{8}{|c|}{ Non chlorate phenols } \\
\hline$m$-, p-cresol & $\mathrm{mg} / \mathrm{kg}$ & ND & 276 & 257 & ND & ND & 0.16 \\
\hline$o$-cresol & $\mathrm{mg} / \mathrm{kg}$ & ND & ND & ND & ND & ND & 0.16 \\
\hline \multicolumn{8}{|l|}{ Dioxins } \\
\hline Total of dioxins & $\mathrm{ng} / \mathrm{kg}$ & 72.2 & 269 & 623 & 884 & 975 & NE \\
\hline Total of furans & $\mathrm{ng} / \mathrm{kg}$ & 5.55 & 74.6 & 135 & 102 & 140 & $\mathrm{NE}$ \\
\hline
\end{tabular}

ND: not detected; NE: values not established for the parameter.

Each extract related to the $100 \%$ SS samples was tested, for all four different periods of natural attenuation, with the six proposed concentrations.

The negative control was performed with $50 \mu \mathrm{L}$ of ultrapure water/Petri dish, the same water used in the extracts. Positive controls were performed with 4-nitroquinoline 1-oxide (4NQO) (Sigma, CAS No. 56-57-5), with concentrations of $0.5 \mu \mathrm{g} /$ Petri dish, for the tests without metabolic activation and with 2Aminoanthracene (2AA) (Sigma, CAS No. 613-13-8), with concentrations of $0.25 \mu \mathrm{g} /$ Petri dish, for the tests with metabolic activation.

The mutagenic potential of each sample was evaluated by quantifying the number of revertants in each dish. Data were statistically evaluated by the software SALANAL (Salmonella Assay Analysis 1.0), selecting the Bernstein or Linear models. The samples were considered mutagenic when the results of both the statistical test ANOVA $(\mathrm{p}<0.05)$ and linear regression $(\mathrm{p}<0.05)$ were significant. The results of mutagenic activity were expressed by the number of revertants per gram equivalent of dry sample tested.

\subsection{Human cells assays}

\subsubsection{Cell culture}

Human-derived hepatoma (HepG2) cells were used as test systems for the MN assay. These cells, purchased from the Rio de Janeiro Cell Bank, were cultivated in minimum essential medium (MEM), supplemented with $10 \%$ bovine serum and $0.1 \%$ antibioticantimycotic solution $(10.000 \mathrm{UI} / \mathrm{mL}$ penicillin and $10 \mathrm{mg} / \mathrm{mL}$ streptomycin), and were kept in disposable culture flasks of $25 \mathrm{~cm}^{2}$ in a BOD incubator at $37{ }^{\circ} \mathrm{C}$ with $5 \% \mathrm{CO}_{2}$.

\subsubsection{Cellular viability test}

In order to determine the non-toxic concentrations for HepG2 cells, the MTT assay (Thiazolyl Blue Tetrazolium Bromide - CAS n. 298-93-1, Sigma) was performed, according to the protocol of Mosmann (1983) with some modifications. Ca. $2.34 \times 10^{4}$ cells were placed in 96-well microplates for stabilization and kept in humid chambers at $37{ }^{\circ} \mathrm{C}$ with $5 \% \mathrm{CO}_{2}$ for $24 \mathrm{~h}$. Thereafter, cells were exposed to the several concentrations of $100 \%$ SS (period 0 ) for an additional $24 \mathrm{~h}$ and then incubated for $4 \mathrm{~h}$ with MTT ( $1 \mathrm{mg} /$ $\mathrm{mL})$, in the same conditions. Negative control was performed with cell culture media and positive control with Triton X-100 at $1 \%$. After this period, MTT was discarded and $100 \mu \mathrm{L}$ of DMSO were added in each well. Plates were then measured in a spectrophotometer with a microplate reader (Multiskan FC - Thermo Scientific) at $540 \mathrm{~nm}$. The tested concentrations were considered cytotoxic when they presented values lower than $80 \%$ of those observed for negative control.

\subsubsection{MN test}

The protocol described by Natarajan and Darroudi (1991), with some modifications, was followed to perform the MN test. Cells were cultivated for a complete cycle $(24 \mathrm{~h})$. Then, simultaneous exposures were performed in single flasks and in triplicate, for $24 \mathrm{~h}$, adding $50 \mu \mathrm{L}$ of each aqueous extracts (10\%, 25\%, $50 \%$ and $100 \%$ SS). The positive control was performed with $50 \mu \mathrm{L}$ methylmethanesulfonate $\left(4 \times 10^{-2} \mathrm{M}\right)$, the negative control with phosphate buffered saline (PBS) and the environmental control with soil aqueous extract. After exposure, cells were washed twice with PBS, and $5 \mathrm{~mL}$ of culture media supplemented with $3 \mu \mathrm{g} / \mathrm{mL}$ cytochalasin B were added in each well. Plates were then incubated for additional $28 \mathrm{~h}$. After this period, cells were harvested, fixed in Carnoy's solution and kept in this solution at $4{ }^{\circ} \mathrm{C}$ before utilization. Later, after at least $12 \mathrm{~h}$, five drops of the fixed cells were placed in clean, cold slides, containing a layer of water. After drying, slides were stained with Giemsa $5 \%$ for $8 \mathrm{~min}$. This assay was performed with extracts of samples from each period of natural attenuation $(0$, 2, 6 and 12 months).

Ca. 1000 binucleated cells with intact cytoplasmic and nuclear membranes, with non-overlapping nuclei of similar sizes, and with the same pattern and intensity of stain, were analyzed per slide under light microscopy $(1,000 \times)$, two slides per repetition. Since all experiments were performed in triplicate, a total of 6000 cells were scored for each concentration and evaluated controls. To evaluate the genotoxic potential of the SS, the results of MN test were compared by the non-parametric test of Mann-Whitney $(\mathrm{p}<0.05)$.

In order to verify the efficiency of the natural attenuation process, the Mann-Whitney test ( $p<0.05$ ) was used to compare the induced effects of a same association of soil/sludge after different periods of natural attenuation to its corresponding period 0 .

\section{Results}

\subsection{Mutagenic activity - Salmonella/microsome microsuspension assay}

Table 2 presents the results obtained with Salmonella/microsome for the solubilized $100 \%$ SS from the several periods of natural attenuation, in the strains TA98 and TA 100. None of the tested samples induced mutagenicity in the strain TA 98, with and without metabolic activation. No significant results were observed in the strain TA 100, without metabolic activation. However, after metabolic activation, the samples related to the periods 0, 2 and 6 months presented a mutagenic potential for this strain (TA 100). Although the results were not significant with ANOVA for the sample corresponding to the period of 2 months, a significant concentration-effect curve was observed, indicating a mutagenic activity for this sample (Fig. 1). For the period of 12 months, this effect was no longer observed, indicating a decrease in the mutagenic potential of the SS after 12 months of natural attenuation.

\subsection{Genotoxicity in human cell culture - HepG2}

The results from the MTT assay related to cellular viability are 
Table 2

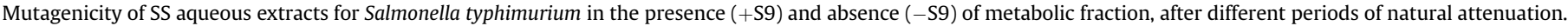

\begin{tabular}{|c|c|c|c|c|c|}
\hline \multirow[t]{3}{*}{ Samples } & \multirow[t]{3}{*}{ Concentrations (mg equivalent of dry SS/plate) } & \multicolumn{4}{|c|}{ Mean of revertants/plate \pm SD } \\
\hline & & \multicolumn{2}{|l|}{ TA 98} & \multicolumn{2}{|l|}{ TA 100} \\
\hline & & $-S 9$ & $+\mathrm{S} 9$ & $-S 9$ & $+\mathrm{S} 9$ \\
\hline Negative control & 0.00 & $42.5 \pm 33.5$ & $53.2 \pm 11.7$ & $181.4 \pm 29.3$ & $197.0 \pm 17.4$ \\
\hline Positive control & - & $476^{\mathrm{b}}$ & $787 \pm 100$ & $1512 \pm 22.6$ & $1715 \pm 284$ \\
\hline \multirow[t]{7}{*}{ SS 0 months } & 6.25 & $70.0 \pm 15.6$ & $49.5 \pm 3.54$ & $193 \pm 10.0$ & $202 \pm 14.0$ \\
\hline & 12.50 & $40.0 \pm 2.65$ & $60.0 \pm 4.24$ & $196 \pm 8.19$ & $215 \pm 11.7$ \\
\hline & 18.75 & - & $58.5 \pm 4.95$ & $206 \pm 4.95$ & $203 \pm 33.2$ \\
\hline & 25.00 & $54.0 \pm 22.6$ & $46.0 \pm 3.00$ & $179 \pm 9.07$ & $210 \pm 14.5$ \\
\hline & 37.50 & $41.5 \pm 4.95$ & $50.5 \pm 10.6$ & $199 \pm 2.83$ & $231 \pm 16.6$ \\
\hline & 50.00 & $36.0 \pm 3.61$ & $53.7 \pm 6.03$ & $190 \pm 7.02$ & $249 \pm 19.6^{*}$ \\
\hline & Mutagenic potency & Negative & Negative & Negative & $935 \pm 0.25$ \\
\hline \multirow[t]{7}{*}{ SS 2 months } & 6.25 & $50.0 \pm 15.6$ & $57.7 \pm 7.37$ & $192 \pm 40.5$ & $204 \pm 30.9$ \\
\hline & 12.50 & $49.7 \pm 9.61$ & $64.3 \pm 6.03$ & $219 \pm 31.2$ & $229 \pm 14.0$ \\
\hline & 18.75 & - & $62.7 \pm 6.43$ & $213 \pm 17.8$ & $220 \pm 19.5$ \\
\hline & 25.00 & $49.7 \pm 9.87$ & $48.7 \pm 1.15$ & $177 \pm 18.6$ & $213 \pm 36.2$ \\
\hline & 37.50 & $36.0 \pm 9.54$ & $53.3 \pm 1.15$ & $208 \pm 14.8$ & $234 \pm 23.1$ \\
\hline & 50.00 & $54.0 \pm 12.7$ & $66.5 \pm 2.12$ & $193 \pm 9.07$ & $255 \pm 25.6$ \\
\hline & Mutagenic potency $^{\mathrm{a}}$ & Negative & Negative & Negative & $1018 \pm 0.31^{c}$ \\
\hline \multirow[t]{7}{*}{ SS 6 months } & 6.25 & $48.5 \pm 10.6$ & $49.7 \pm 1.15$ & $185 \pm 14.1$ & $199 \pm 33.9$ \\
\hline & 12.50 & $47.3 \pm 9.2$ & $50.7 \pm 4.04$ & $187 \pm 6.51$ & $229 \pm 17.4$ \\
\hline & 18.75 & - & $55.7 \pm 11.1$ & $192 \pm 24.5$ & $248 \pm 11.5^{*}$ \\
\hline & 25.00 & $51.7 \pm 6.66$ & $55.7 \pm 4.51$ & $160 \pm 21.5$ & $224 \pm 22.7$ \\
\hline & 37.50 & $38.0 \pm 5.66$ & $65.0 \pm 5.29$ & $209 \pm 18.5$ & $230 \pm 17.1$ \\
\hline & 50.00 & $57.5 \pm 9.19$ & $50.0 \pm 20.5$ & $206 \pm 15.7$ & $227 \pm 16.0$ \\
\hline & Mutagenic potency $^{a}$ & Negative & Negative & Negative & $689 \pm 0.25$ \\
\hline \multirow[t]{7}{*}{ SS 12 months } & 6.25 & $63.0 \pm 4.24$ & $58.0 \pm 3.46$ & $188 \pm 2.83$ & $215 \pm 14.6$ \\
\hline & 12.50 & $33.5 \pm 6.36$ & $54.3 \pm 12.1$ & $159 \pm 10.8$ & $206 \pm 6.56$ \\
\hline & 18.75 & - & $46.3 \pm 0.58$ & $183 \pm 8.39$ & $212 \pm 3.21$ \\
\hline & 25.00 & $29.5 \pm 2.12$ & $50.3 \pm 7.02$ & $175 \pm 17.0$ & $211 \pm 4.04$ \\
\hline & 37.50 & $31.0 \pm 1.41$ & $40.3 \pm 11.0$ & $155 \pm 3.51$ & $212 \pm 7.37$ \\
\hline & 50.00 & $29.5 \pm 3.54$ & $33.3 \pm 4.04$ & $144 \pm 25.9$ & $211 \pm 23.3$ \\
\hline & Mutagenic potency $^{a}$ & Negative & Negative & Negative & Negative \\
\hline
\end{tabular}

*Significant for ANOVA ( $\mathrm{p}<0.05$ ).

a Calculated from the slope of the linear portion of the concentration-effect curve, using linear regression analysis, considering that the slope is always proportional to the potency of the sample, quantitatively expressed in number of revertants/g equivalent of dry sample \pm standard deviation.

b Value corresponding to a single plate.

${ }^{c}$ Indicative of mutagenicity (not significant for ANOVA).

presented in Table 3 . The test was performed with 5 different concentrations of $100 \%$ SS extract, before the period of natural attenuation (period 0 ). The only concentration presenting cell viability above $80 \%$ was $10 \mu \mathrm{L} / \mathrm{mL}$ culture media. Therefore, this concentration was chosen to be used in the MN test.

Table 4 presents the results obtained in relation to the frequency of MN presented in HepG2 binucleated cells after exposure to different solubilized SS. Results indicated that, for the samples of period 0 and 2 months, all tested concentrations induced a significant genotoxic effect in HepG2 cells, when compared to the NC (except for concentration 10\%, for samples of 2 months). However, no significant genotoxic effect was observed for the samples over 6 and 12 months of natural attenuation.

Comparing the frequencies of MN presented in HepG2 cells, after the different periods of natural attenuation, with the same concentration of SS, it is possible to observe a significant decrease in this parameter for all tested concentrations (Fig. 2). After 2 months of natural attenuation, the concentration $10 \%$ showed values closer to those presented by the negative control, while for the other concentrations this decrease became significant after 6 months, being more pronounced after 12 months of attenuation.

\section{Discussion}

As SS has been used as agricultural fertilizer by several countries and due to possible impact that it may cause to the environment where it is disposed, a constant monitoring must be performed to certify its environmental effects as well as its potential risks that it can promote to human health. One strategy for this evaluation would be the use of several bioassays, capable of identifying the bioavailability of the group of contaminants present in SS, and thus to infer the actual risk of exposure of organisms to this residue (Alvarenga et al., 2007).

In the present study, the Salmonella/microsome assay was performed with TA 98 and TA 100 strains, which, according to Silva Júnior and Vargas (2009), are the most used strains in environmental mutagenesis studies.

Ottaviani et al. (1993) also employed the strains TA 98 and TA 100 to evaluate the mutagenic potential of SS in Rome, Italy. However, even with in presence of polychlorinated biphenyls (PCBs), the authors observed an absence of mutagenicity in the SS, and recorded a cytotoxic effect in doses above $5 \mathrm{mg} /$ plate dish. The detection of mutagenicity in SS samples from industrial origin using the Salmonella assay with the strains TA 98 and TA 100 was also reported by Klee et al. (2004). The strain TA 98 was also used by Donnelly et al. (1990) to evaluate the mutagenicity of organic compounds presented in soils receiving SS incorporation. By the positive mutagenic responses, the authors suggested that the incorporation of SS in soils contributed to an increase of mutagens in the environment. According to our results, we also suggest that the studied SS can be a source of potential mutagenic contaminants, and that, when deposited in the environment, it can represent risks to the exposed organisms.

The absence of significant results for the strain TA 98 indicated that the tested SS was not capable of inducing frameshift mutations, even with metabolic activation. However, the mutagenicity 

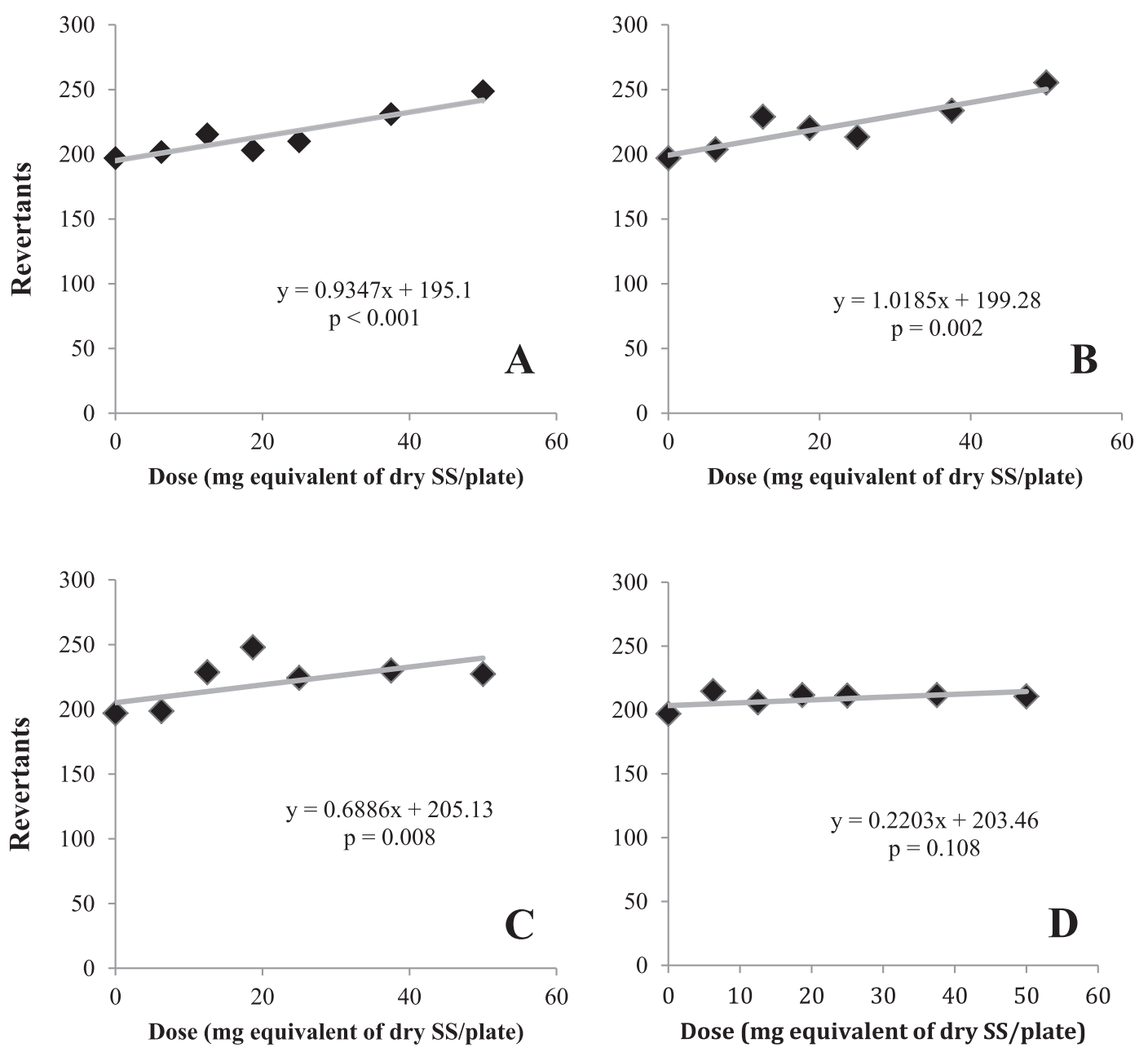

\section{- Observed Predicted (linear model)}

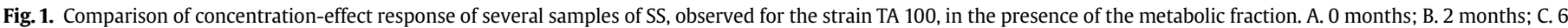

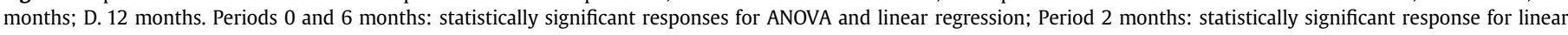
regression; Period 12 months: absence of statistical significance.

Table 3

Effect of the SS $100 \%$ aqueous extract (period 0) on the viability of HepG2 cells exposed to different concentrations of this sample.

\begin{tabular}{llllll}
\hline SS 100\% (period 0) & \multicolumn{5}{c}{ Concentrations (mg equivalent of dry SS/flasks) } \\
\cline { 2 - 6 } & 3.10 & 6.25 & 9.40 & 12.5 & 25.0 \\
\hline Viability & $71.2 \%$ & $82.3 \%$ & $73.3 \%$ & $68.6 \%$ & $62.0 \%$ \\
\hline
\end{tabular}

observed for TA 100 , which detects mutations by replacing base pairs (Maron and Ames, 1983) in the presence of S9, suggests that the SS contains pro-mutagens capable of inducing this kind of mutations, only after being metabolized. Similar results were also observed by Pérez et al. (2003), when the authors evaluated a SS of domestic and mixed (domestic and industrial) origin, whose mutagenic activity was only observed for the strains TA 98 and 100 in the presence of metabolic fraction.

Mammalian cell culture assays have been widely used in the investigation of the genotoxic potential of environmental pollutants (Matsumoto et al., 2005; Cardozo et al., 2006; Mazzeo et al., 2013). In our studies, the HepG2 cells shown to be very sensitive in the detection of genotoxicity of SS.

Bakare et al. (2007) evaluated the potential induction of DNA damage of SS leachate from municipal origin in a human cell culture. The authors verified a significant increase of damage in lymphocytes culture after exposure to SS, indicating a potential risk to humans. Studies performed by Gajski et al. (2011) also demonstrated a significant increase in the frequency of micronucleus in an in vitro test performed with human lymphocytes exposed to leached SS. These authors concluded that the tested SS samples were genotoxic for lymphocytes, being capable of inducing adverse effects in a human population exposed to it. A significant increase on the frequency of micronucleus in polychromatic erythrocytes of rats after 15 days of exposure to low concentrations of leached SS, was also recorded by Tewari et al. (2005). The authors concluded that these effects were possibly due to the combined action of contaminants presented in the SS. Thus, the presence of toxic substances in aqueous extracts of SS may, by percolation in the soil, compromise the subterraneous and superficial waters, disseminating genotoxic substances, and, therefore, represents a potential risk to the public health.

The genotoxic effect observed in the MN test with HepG2 cells 
Table 4

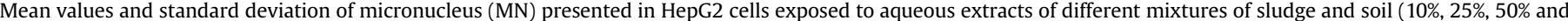
$100 \%$ sludge).

\begin{tabular}{|c|c|c|c|c|}
\hline Treatment & Initial sample & 2 months sample & 6 months sample & 12 months sample \\
\hline Negative control & $27.3 \pm 3.00$ & $24.0 \pm 2.00$ & $29.0 \pm 3.22$ & $24.8 \pm 3.41$ \\
\hline Soil & $30.7 \pm 2.77$ & - & - & - \\
\hline Positive control & $122.6 \pm 10.8^{*}$ & $130.9 \pm 13.5^{*}$ & $104.7 \pm 13.2^{*}$ & $102.2 \pm 12.4^{*}$ \\
\hline SS $10 \%^{\text {a }}$ & $41.4 \pm 5.82^{*}$ & $21.5 \pm 4.23$ & $31.6 \pm 2.43$ & $25.5 \pm 5.00$ \\
\hline SS $25 \%^{\text {a }}$ & $48.5 \pm 2.74^{*}$ & $53.7 \pm 2.73^{*}$ & $30.7 \pm 3.32$ & $23.6 \pm 3.00$ \\
\hline SS $50 \%^{a}$ & $56.8 \pm 3.82^{*}$ & $56.8 \pm 2.79 *$ & $31.3 \pm 2.51$ & $24.7 \pm 1.86$ \\
\hline SS $100 \%^{b}$ & $63.8 \pm 1.94^{*}$ & $67.2 \pm 5.23^{*}$ & $31.3 \pm 1.36$ & $26.1 \pm 3.53$ \\
\hline
\end{tabular}

$\mathrm{MN} / 1000$ binucleated cells $\pm \mathrm{SD}$.

2000 binucleated HepG2 cells were counted for each sample in 3 experiments in parallel.

*Statistically significant when compared to the negative control $(\mathrm{p}<0.05)$ using the Mann-Whitney test.

a Representing $12.5 \mathrm{mg}$ equivalent of dry sample (10\%, 25\% and 50\% sludge).

b Representing $6.25 \mathrm{mg}$ equivalent of dry SS $100 \%$.

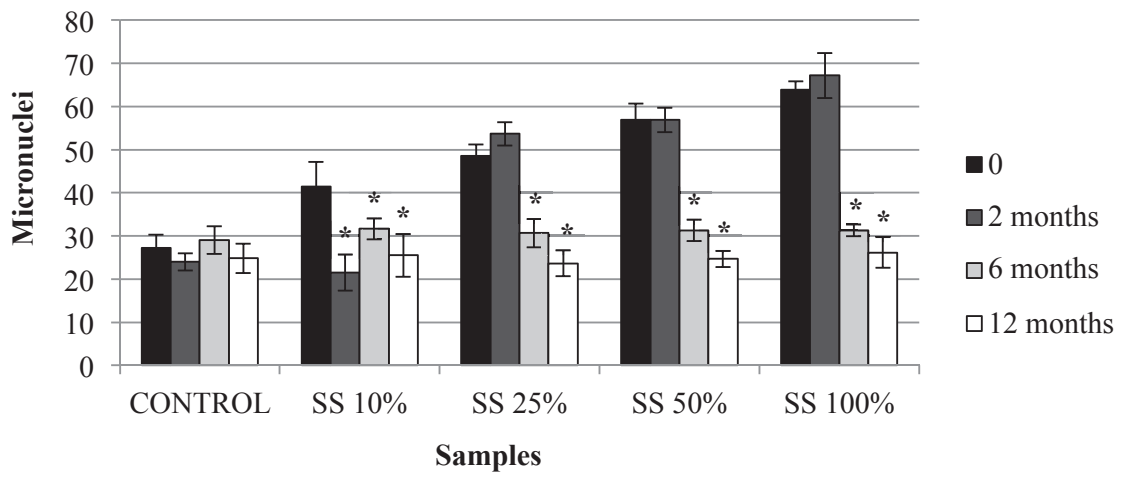

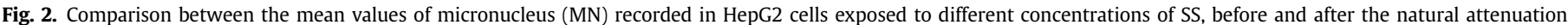
process. *Significant decrease between the non-biodegraded concentration and its respective biodegraded concentration, according to the Mann-Whitney test ( $\mathrm{p}<0.05$ ).

may be due to the presence of $m$ - and $p$-cresol in the aqueous extract of the SS, since the significant frequencies of MN were observed in the extracts related to the periods of 0 and 2 months of natural attenuation, in which these substances were also detected. A reduction of MN frequency was also detected, in levels closer to the negative control, in 6 and 12 months samples, coinciding with the decrease of the $m$ - and $p$-cresol concentration. However, this genotoxicity observed could also be due to the presence of other substances not identified by chemical analysis, which can present a combined action in inducing this alteration.

Hikiba et al. (2005) observed induction of chromosomal aberration (achromatic lesions and breaks) in Syrian hamster embryo cells (in vitro test) exposed to 43.256, 86.512 and $108.14 \mathrm{mg} / \mathrm{L}$ of $m$ cresol, which were higher than the ones found in the present study (3.70 $\mathrm{mg} / \mathrm{L}, 4.21 \mathrm{mg} / \mathrm{L}, 0.78 \mathrm{mg} / \mathrm{L}$ and $0.06 \mathrm{mg} / \mathrm{L}$ for the periods of 0 , 2, 6 and 12 months of natural attenuation, respectively). This parameter had its frequency increased to the concentrations of $10.814,32.442$ and $108,14 \mathrm{mg} / \mathrm{L}$ in the presence of the metabolic activation fraction. Authors suggested that, after metabolic conversion, $m$-cresol became a potential genotoxic chemical. According to Hamaguchi and Tsutsui (2000), $m$-cresol induced DNA alterations in Syrian hamster embryo cells maintained in culture with exogenous metabolic activation, which led the authors to conclude that this substance is genotoxic to mammalian cells. Other authors also concluded that SS toxicity could be more related to the presence of phenolic compounds (e.g., cresol), than to metals and persistent organic pollutants (POPs) (Roig et al., 2012).

Since the HepG2 cells used in this study present a metabolic enzymatic system of phases I and II, acting in the activation and detoxification of reactive chemicals to DNA (Knasmüller et al., 1998, 2004), we believe that the observed genotoxic effect is related to the action of cresol, as well as to a possible combined action of unknown substances present in SS that degraded within the same period of cresol. The results obtained by the microsuspension assay with Salmonella suggest that other substances with mutagenic potential were also present in the SS, seeing as mutagenic activity was observed similarly for SS samples of 0 and 6 months of natural attenuation. Because the concentration of cresol in the SS 6 months was low, we concluded that there were other contaminants with mutagenic potential, not identified by chemical analyses. Moreover, other studies reported that cresol was not capable of inducing mutagenic effect in the S. typhimurium strains TA 98 and TA 100, both in the presence and absence of metabolic fraction S9 mix (Kubo et al., 2002).

When in high doses, dioxins may induce a wide variety of effects in humans, such as cancer, endocrine dysfunction, immune toxicity, physiological and reproductive disorders, neurotoxicity, among others (Schecter et al., 2011). However, data related to genotoxic effects on human beings are considered inconclusive and inconsistent. Although most of these studies highlight that dioxins and furans are not genotoxic to animals, including humans (ATSDR, 1998), these studies are based on small samples, which do not certify this action. Valic et al. (2004) reported that patients intoxicated with 2,3,7,8-tetrachlorodibenzo-p-dioxin (TCDD), with a blood concentration of $85,600 \mathrm{pg} / \mathrm{g}$ and $17,700 \mathrm{pg} / \mathrm{g}$, presented a significant frequency of MN, indicating a genotoxic effect of TCDD. In our work, despite an increase in the values of dioxin in SS samples after 6 and 12 months of natural attenuation (Table 1), the concentrations of these compounds did not induce an increase in the micronucleus frequency in HepG2 cells and mutagenicity in the assays with Salmonella. In previous studies, 2,3,7,8tetrachlorodibenzo-p-dioxin, considered the most toxic substance 
among this class of compounds, did not present mutagenic activity for the strains TA 98 and TA 100 in Ames test (Geiger and Neal, 1981).

However, as SS is a complex mixture, we cannot disprove a possible mixture effect between its components, which could lead to the observed mutagenicity. According to Oleszczuk (2008), since SS is composed by a complex matrix, constituted by several substances, it is difficult to attribute the observed toxicological effect to specific compounds, because several chemical interactions may occur between the different substances presented.

A significant decrease in the observed effects during the period of natural attenuation, for both the MN test and the Salmonella/ microsome microsuspension assay, suggest a need for the use of methods of decontamination before the disposal of the SS in agricultural soils. Even in low concentrations, the studied SS without pre-treatment showed to be capable of inducing genetic damage in human cells, being characterized as a potential contaminant to the environment.

Other authors also reported that, after performing decontamination treatment in SS, there was a significant decrease in mutagenic effects, confirming the importance of the treatment of SS before its deposition in the environment (Gajski et al., 2011). According to Roig et al. (2012), the pre-treatment of SS, before its disposal into the environment, directly influences some of its properties, for example, its toxicity. After investigating different types of SS, these authors concluded that those without pretreatment presented the highest toxicity index in assays with plants and bacteria, while SS that was submitted to composting was considered 2 to 3 times less toxic than the others. Ramírez et al. (2008) evaluated the toxic potential of SS from urban sewage treatment plants in 3 different plants and concluded that the composting significantly reduced the phytotoxicity of SS. Studies performed by Domene et al. (2008) also indicated that, to avoid impacts in the edaphic community, the SS must be stabilized before being applied to the soil. Donnelly et al. (1990) also verified a decrease in mutagenic activity with the increase in the period after the disposal of the SS in the soil. The authors observed that the mutagenic substances initially present in the SS persisted for long periods in the soil, which makes a period of approximately two years necessary for the mutagenic activity in the studied soils to decrease to basal levels. However, in the present study, a decrease in the mutagenic potential of the SS was already observed after 6 months of natural attenuation, culminating in a more pronounced decrease after 12 months. The faster decline of the toxicity of the studied sludge is probably due to the initial toxic potentiality of this sludge, which confirms that different types of sludges require different degradation periods. These results described in the literature, associated to those observed in the present study, also indicate the need of pre-processing SS in order to allow its use in agriculture, and consequently, its disposal into the environment.

\section{Conclusion}

The use of SS in agricultural soils without prior treatment may contribute to an increase in the genotoxic and mutagenic activity of the soil, resulting in damage to the environment and the exposed organisms. The presence of genotoxic and mutagenic substances in the aqueous extract of the studied SS indicates that the SS contaminants can be carried to other physical media, contaminating ground and surface water and thus become bioavailable. By the results obtained in this work, it is possible to infer that the effects observed for this SS seems to be related to an action of promutagens, since the mutagenic activity was more related to assays using hepatic metabolic activation (S9 fraction).

The MN test with HepG2 cells and the Salmonella/microsome assay with the strain TA 100 showed to be a very sensitive tool for the detection of genotoxic and mutagenic damages from the action of the studied SS. The use of SS as fertilizer should be done only after the completion of its detoxification, being the process of natural attenuation very efficient for this purpose. However, we suggest that more than 6 months of natural attenuation should be provided to ensure the total elimination of substances with genotoxic and mainly mutagenic actions.

\section{Conflict of interest}

The authors declare that they have no conflict of interest.

\section{Acknowledgments}

The authors would like to thank the São Paulo Research Foundation, for the financial support (process no. 2009/09665-0).

\section{Appendix A. Supplementary data}

Supplementary data related to this article can be found at http:// dx.doi.org/10.1016/j.chemosphere.2016.08.060.

\section{References}

ABNT - Associação Brasileira de Normas Técnicas, 2004. NBR 10006: Procedimento para obtenção de extrato solubilizado de resíduos sólidos (Procedure for Obtention of Solubilized Extraction of Solid Wastes). ABNT, Rio de Janeiro.

Alvarenga, P., Palma, P., Gonçalves, A.P., Fernandes, R.M., Cunha-Queda, A.C., Duarte, E., Vallini, G., 2007. Evaluation of chemical and ecotoxicological characteristics of biodegradable organic residues for application to agricultural land. Environ. Int. 33, 505-513.

Aparicio, I., Santos, J.L., Alonso, E., 2009. Limitation of the concentration of organic pollutants in sewage sludge for agricultural purposes: a case study in South Spain. Waste Manag. 29, 1747-1753.

ATSDR-Agency for Toxic Substances and Disease Registry, 1998. Toxicological Profile for Chlorinated dibenzo-p-dioxins. U.S. Department of Health and Human Services, Public Health Service, Atlanta, GA.

Baderna, D., Colombo, A., Amodei, G., Cantù, S., Teoldi, F., Cambria, F., Rotella, G., Natolino, F., Lodi, M., Benfenati, E., 2013. Chemical-based risk assessment and in vitro models of human health effects induced by organic pollutants in soils from the Olona valley. Sci. Total Environ. 463-464, 790-801.

Bakare, A.A., Pandey, A.K., Bajpayee, M., Bhargav, D., Chowdhuri, D.K., Singh, K.P. Murthy, R.C., Dhawan, A., 2007. DNA damage induced in human peripheral blood lymphocytes by industrial solid waste and municipal sludge leachates. Environ. Mol. Mutagen 48, 30-37.

Bonassi, S., Znaor, A., Ceppi, M., Lando, C., Chang, W., Holland, N., Kirsch-Volders, M. Zeiger, E., Ban, S., Barale, R., Bigatti, M., Bolognesi, C., Cebulska-Wasilewska, A., Fabianova, E., Fucic, A., Hagmar, L., Joksic, G., Martelli, A., Migliore, L. Mirkova, E., Scarfi, M., Zijno, A., Norppa, H., Fenech, M., 2007. An increased micronucleus frequency in peripheral blood lymphocytes predicts the risk of cancer in humans. Carcinogenesis 28, 625-631.

Cardozo, T.R., Rosa, D.P., Feiden, I.R., Rocha, J.A.V., D’avila de Oliveira, N.C. Pereira, T.S., Pastoriza, T.F., Marques, D.M., Lemosa, C.T., Terra, N.R., Vargas, V.M.F., 2006. Genotoxicity and toxicity assessment in urban hydrographic basins. Mutat. Res. 603, 83-96.

Cifci, D.I., Kinaci, C., Arikan, O.A., 2013. Occurrence of phthalates in sewage sludge from three wastewater treatment plants in Istanbul, Turkey. Clean. - Soil Air Water 41, 851-855.

Cincinelli, A., Martellini, T., Misuri, L., Lanciotti, E., Sweetmen, A., Laschi, S. Palchetti, I., 2012. PBDEs in Italian sewage sludge and environmental risk of using sewage sludge for land applications. Environ. Pollut. 161, 229-243.

Claxton, L.D., Umbuzeiro, G.A., Demarini, D., 2010. The Salmonella mutagenicity assay: the stethoscope of genetic toxicology for the 21st century. Environ. Health Perspect. 118, 1515-1522.

Domene, X., Ramírez, W., Mattana, S., Alcañiz, J.M., Andrés, P., 2008. Ecological risk assessment of organic waste amendments using the species sensitivity distribution from a soil organisms test battery. Environ. Pollut. 155, 227-236.

Donnelly, K.C., Thomas, J.C., Anderson, C.S., Brown, K.W., 1990. The influence of application rate on the bacterial mutagenicity of soil amended with municipal sewage sludge. Environ. Pollut. 68, 147-159.

Farré, M., Barceló, D., 2003. Toxicity testing of wastewater and sewage sludge by biosensors, bioassays and chemical analysis. TRAC-Trend. Anal. Chem. 22 299-310.

Gajski, G., Oreščanin, V., Garaj-Vrhovac, V., 2011. Cytogenotoxicity of sewage sludge leachate before and after calcium oxide-based solidification in human lymphocytes. Ecotox. Environ. Safe. 74, 1408-1415. 
Geiger, L.E., Neal, R.A., 1981. Mutagenicity testing of 2,3,7,8-tertachlorodibenzo-pdioxin in histidine auxotrophs of Salmonella typhimurium. Toxicol. Appl. Pharm. 59, 125-129.

Hamaguchi, F., Tsutsui, T., 2000. Assessment of genotoxicity of dental antiseptics: ability of phenol, guaiacol, p-phenolsulfonic acid, sodium hypochlorite, pchlorophenol, m-cresol or formaldehyde to induce unscheduled DNA synthesis in cultured Syrian hamster embryo cells. Jpn. J. Pharm. 83, 273-276.

Hikiba, H., Watanabe, E., Barret, C., Tsutsui, T., 2005. Ability of fourteen chemica agents used in dental practice to induce chromosome aberrations in Syrian hamster embryo cells. J. Pharmacol. Sci. 97, 146-152.

Kado, N.Y., Langley, D., Eisenstadt, E., 1983. A simple modification of Salmonella liquid incubation assay. Increased sensitivity for detecting mutagens in human urine. Mutat. Res. 121, 25-32.

Klee, N., Gustavsson, L., Kosmehl, T., Engwall, M., Erdinger, L., Braunbeck, T., Hollert, H., 2004. Changes in toxicity and genotoxicity of industrial sewage sludge samples containing nitro- and amino-aromatic compounds following treatment in bioreactors with different oxygen regimes. Environ. Sci. Pollut. R $11,313-320$.

Knasmüller, S., Gottmann, E., Steinkellner, H., Fomin, A., Pickl, C., Paschke, A., Göd, R., Kundi, M., 1998. Detection of genotoxic effects of heavy meta contaminated soils with plant bioassays. Mutat. Res. 420, 37-48.

Knasmüller, S., Mersch-Sundermann, V., Kevekordes, S., Darroudi, F., Huber, W.W. Hoelzl, C., Bichler, J., Majer, B.J., 2004. Use of human-derived liver cell lines for the detection of environmental and dietary genotoxicants current state of knowledge. Toxicology 198, 315-328.

Kubo, T., Urano, K., Utsumi, H., 2002. Mutagenicity characteristics of 225 environmental chemicals. J. Health Sci. 48, 545-554.

Maron, D.M., Ames, B.N., 1983. Revised methods for the Salmonella mutagenicity test. Mutat. Res. 113, 173-214.

Matsumoto, S.T. Rigonato, J., Mantovani, M.S., Marin-Morales, M.A., 2005. Evaluation of the genotoxic potential due to the action of an effluent contaminated with chromium, by the comet assay in CHO-K1 cultures. Caryologia 58, 40-46.

Mazzeo, D.E.C., Matsumoto, S.T., Levy, C.E., Angelis, D.F., Marin-Morales, M.A., 2013. Application of micronucleus test and comet assay to evaluate BTEX biodegradation. Chemosphere 90, 1030-1036.

Mazzeo, D.E.C., Fernandes, T.C.C., Levy, C.E., Angelis, D.F., Fontanetti, C.S., MarinMorales, M.A., 2015. Monitoring the natural attenuation of a sewage sludge toxicity using the Allium cepa test. Ecol. Indic. 56, 60-69.

Megharaj, M., Ramakrishnan, B., Venkateswarlu, K., Sethunathan, N., Naidu, R., 2011. Bioremediation approaches for organic pollutants: a critical perspective. Environ. Int. 37, 1362-1375.

Mills, M.A., Bonner, J.S., Mcdonald, T.J., Page, C.A., Autenrieth, R.L., 2003. Intrinsic bioremediation of a petroleum-impacted wetland. Mar. Pollut. Bull. 46, 887-899.

Mosmann, T., 1983. Rapid Colorimetric Assay for cellular growth and survival: application to proliferation and cytotoxicity assays. J. Immunol. Methods 65, 55-63.

Natarajan, A.T., Darroudi, F., 1991. Use of human hepatoma cells for in vitro metabolic activation of chemical mutagens/carcinogens. Mutagenesis 6, 399-403.

Oleszczuk, P., 2008. Forms of polycyclic aromatic hydrocarbon in the formation of sewage sludge toxicity to Heterocypris incongruens. Sci. Total Environ. 404, 94-102.

Ottaviani, M., Crebelli, R., Fuselli, S., La Rocca, C., Baldassarri, L.T., 1993. Chemical and mutagenic evaluation of sludge from a large wastewater treatment plant. Ecotox. Environ. Safe. 26, 18-32.

Pathak, A., Dastidar, M.G., Sreekrishnan, T.R., 2009. Bioleaching of heavy metals from sewage sludge: a review. J. Environ. Manag. 90, 2343-2353.

Pérez, S., Reifferscheid, G., Eichhorn, P., Barceló, D., 2003. Assesment of the mutagenic potency of sewage sludges contaminated with polycyclic aromatic hidrocarbons by an Ames fluctuation assay. Environ. Chem. 22, 2576-2584.

Ramírez, W.A., Domene, X., Ortiz, O., Alcañiz, J.M., 2008. Toxic effects of digested, composted and thermally-dried sewage sludge on three plants. Bioresour Technol. 99, 7168-7175.

Rathod, P.H., Patel, J.C., Shah, M.R., Jhala, A.J., 2009. Recycling gamma irradiated sewage sludge as fertilizer: a case study using onion (Alium cepa). Appl. Soil Ecol. 41, 223-233.

Roig, N., Sierra, J., Nadal, M., Navalón-Madrigal, P., Schuhmacher, M., Domingo, J.L., 2012. Relationship between pollutant content and ecotoxicity of sewage sludges from Spanish wastewater treatment plants. Sci. Total Environ. 425, 99-109.

Schecter, A.J., Colacino, J.A., Birnbaum, L.S., 2011. Dioxins: health effects. In: Nriagu, J. (Ed.), Encyclopedia of Environmental Health. Elsevier, Amsterdam, pp. 93-100.

Silva Júnior, F.M.R., Vargas, V.M.F., 2009. Using the Salmonella assay to delineate the dispersion routes of mutagenic compounds from coal wastes in contaminated soil. Mutat. Res. 673, 116-123.

Solano, M.L.M., Lima, P.L.A., Luvizutto, J.F.L., Silva, P.R.P., Umbuzeiro, G.A., Camargo, J.L.V., 2009. In vivo genotoxicity evaluation of a treated urban sewage sludge. Mutat. Res. 676, 69-73.

Tewari, A., Chauhan, L.K.S., Kumar, D., Gupta, S.K., 2005. Municipal sludge leachateinduced genotoxicity in mice - a subacute study. Mutat. Res. 587, 9-15.

Valic, E., Jahn, O., Papke, O., Winker, R., Wolf, C., Rudiger, W.H., 2004. Transient increase in micronucleus frequency and DNA effects in the comet assay in two patients after intoxication with 2,3,7,8-tetrachlorodibenzo-p-dioxin. Int. Arch. Occ. Env. Health 77, 301-306.

Van Der Water, F.M., Havinga, J. Ravesloot, W.T. Horbach, G.J.M.J. Scoonen, W.G.EJ. 2011. High content screening analysis of phospholipidosis: validation of a 96well assay with CHO-K1 and HepG2 cells for the prediction of in vivo based phospholipidosis. Toxicol. In Vitro 25, 1870-1882. 